\title{
The cost-effectiveness of adding tomosynthesis to mammography-based breast cancer screening: an economic analysis
}

\author{
Sonya Cressman PhD MBA, Colin Mar MD, Janette Sam MRT, Lisa Kan MSc, Caroline Lohrisch MD, \\ John J. Spinelli PhD MSc
}

\section{Abstract}

Background: Observational studies show that digital breast tomosynthesis (DBT) combined with digital mammography (DM) can reduce recall rates and increases rates of breast cancer detection. The objective of this study was to examine the cost-effectiveness of DBT plus DM versus DM alone in British Columbia and to identify parameters that can improve the efficiency of breast cancer screening programs.

Methods: We conducted an economic analysis based on data from a cohort of screening participants in the BC Cancer Breast Screening Program. The decision model simulated lifetime costs and outcomes for participants in breast cancer screening who were aged 40-74 years between 2012 and 2017. We analyzed rates of health care resource utilization, health state costs and estimated incremental cost-effectiveness ratios (ICERs), to measure incremental cost differences per quality-adjusted life years (QALYs) gained from the addition of DBT to DM-based screening, from the government payer's perspective.

Results: The model simulated economic outcomes for 112249 screening participants. We found that the ICER was highly sensitive to recall rate reductions and insensitive to parameters related to cancer detection. If DBT plus DM can reduce absolute recall rates by more than $2.1 \%$, the base-case scenario had an ICER of $\$ 17149$ per QALY. At a willingness-to-pay threshold of $\$ 100000$ per QALY, more than $95 \%$ of the probabilistic simulations favoured the adoption of DBT plus DM versus DM alone. The ICER depended heavily on the ability of DBT plus DM to reduce recall rates.

Interpretation: The addition of DBT to DM would be considered cost-effective owing to the low positive predictive value of screening with DM alone. Reductions in false-positive recall rates should be monitored closely.

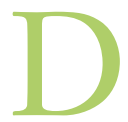

igital breast tomosynthesis (DBT) is an imaging technique that may improve the specificity and positive predictive value of breast cancer screening. ${ }^{1}$ The new technology provides multiple planar images per breast screened, thereby enhancing the ability to distinguish between malignant and benign characteristics on digital mammography (DM) screening exams. Observational studies have shown that using DBT as an adjunct to DM screening reduces the rate of recall exams ${ }^{2-14}$ and increases rates of cancer detection. ${ }^{1,3,6,7,13,15-17}$ Meta-analysis suggests that reductions in recall rates vary widely, with the highest reduction rates from North American trials. ${ }^{18}$ The combined use of DBT plus DM for breast screening has been adopted in regions in the United States with greater socioeconomic resources. ${ }^{19}$ The preventive services task forces in Canada and the US, however, do not recommend the use of adjunct DBT in normal-risk breast screening programs. ${ }^{19-21}$

The underlying hypothesis driving the adoption of adjunct DBT assumes that there would be a reduction in total screening costs associated with less diagnostic work-up for false positives. There are, however, concerns that the extra time required for radiologists to interpret the numerous additional images and the data-storage requirements may introduce costs that outweigh any potential savings. ${ }^{22,23}$ As screening programs perform high volumes of breast exams, the decision to supplement DM-based screening with DBT requires data-driven analyses of the total costs and all downstream outcomes involved.

Population-based cohort models can rapidly account for longterm costs, outcomes and uncertainty in decision-making. ${ }^{24}$

Competing interests: None declared.

This article has been peer reviewed.

Correspondence to: Sonya Cressman, sonya_cressman@sfu.ca CMAJ Open 2021. DOI:10.9778/cmajo.20200154 
Three studies have been published to estimate the costeffectiveness of adjunct DBT for breast screening in the US. ${ }^{25-27}$ These studies have offered information to support decisions about the population at risk, based on the natural history of breast cancer and how the cost-effectiveness varies with known risks such as age and breast density. The economic simulations to date suggest that, depending on the cost of DBT and the way cancer outcomes are simulated, the results generated can vary extensively, indicating a need for more economic evidence and definitive analysis of uncertainty. A recent review by the Canadian Agency for Drugs and Technologies in Health calls for economic evidence on the use of DBT in screening that is generalizable to the Canadian context. ${ }^{19-21}$ The purpose of our study, therefore, is to provide Canadian evidence on the economics of breast cancer screening and insight into which aspects of screening may be optimized to improve program efficiency. Specifically, we aimed to examine the cost-effectiveness of DBT plus DM versus DM alone in British Columbia and to identify parameters that can improve the efficiency of breast cancer screening programs.

\section{Methods}

\section{Study design and setting}

We conducted an economic analysis of the additional costs and quality-adjusted life years (QALYs) from adding DBT to breast cancer screening programs. We used data from a provincially funded breast cancer screening program for participants aged $40-74$ years in BC.

\section{Model overview}

We developed a cost-effectiveness model to simulate the long-term economic impact of supplementing DM with DBT. Policy-makers in BC are considering the adoption of DBT as an adjunct to the provincial DM-based breast cancer screening program. The model was co-developed with stakeholders from BC Cancer Breast Screening and clinical staff, who participated in the design of the model (Figure 1).

We used data from the BC Cancer Breast Screening Program and the BC Cancer Registry for all new screening participants, aged 40-74 years, with an initial, "index," screening exam received between Jan. 1, 2012, and Dec. 31, 2017. We assumed $100 \%$ return rates for biennial exams over 23 years (i.e., the period of screening eligibility) to estimate the maximum possible increase in costs from the addition of DBT. Long-term cancer outcomes were simulated with data from former screening participants who developed breast cancer between Jan. 1, 2007, and Dec. 31, 2016. Further details about the modelling approach and permitted transitions are provided in Appendix 1, available at www.cmajopen. ca/content/9/2/E443/suppl/DC1.

The total costs and benefits were simulated from the government payer's perspective over a 40-year time horizon, encompassing years of screening eligibility and mortality from breast cancer and other causes. The isolated and combined parameter uncertainty was assessed with deterministic and probabilistic sensitivity analyses, respectively.

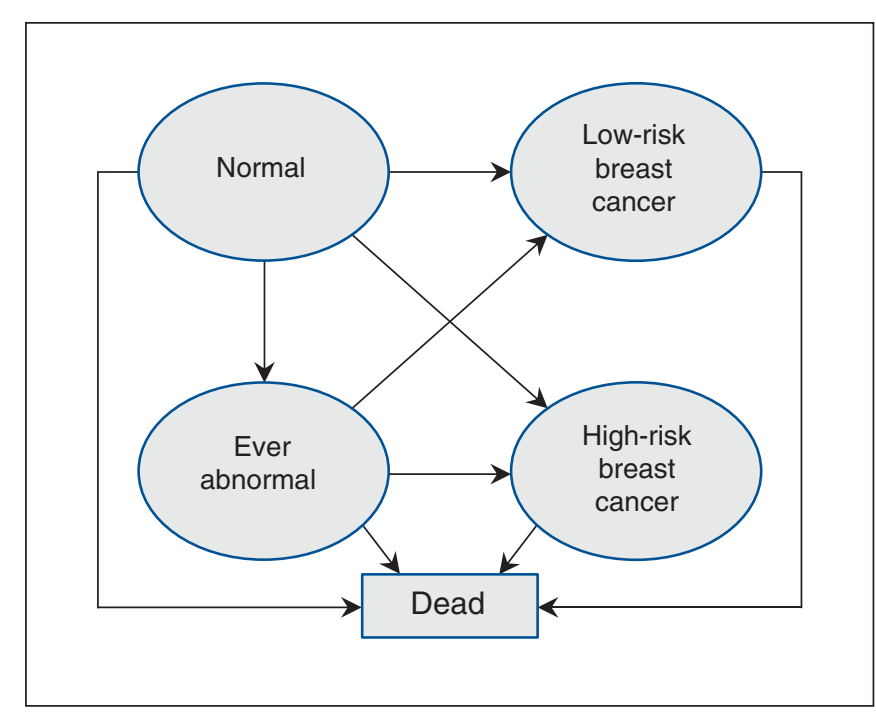

Figure 1: Health states and permitted transitions in the model. Any abnormal exam resulted in movement through the "ever abnormal" health state. High- and low-risk breast cancer were based on stage and histology fields. All in situ and stage I breast cancer, excluding triple-negative breast cancer, were subgrouped as "low risk." All other breast cancer was assigned to the "high risk" subgroup.

\section{Screening outcomes}

The screening outcomes were defined as follows. Recall rate was the proportion of mammograms classified as abnormal according to the radiologist's interpretation. The cancer rate was the number of participants with cancer diagnosed within 1 year of a mammogram, per 1000 screens. The cancer detection rate was the number of participants with a cancer diagnosis within 12 months of an abnormal screen, per 1000 abnormal screening exams. The interval cancer rate was the number of participants with a confirmed incident cancer within 0-12 months of their last screening exam that was negative, per 1000 normal screening exams.

The screening outcome measures were defined for screening participants who had their baseline exam before Dec. 31, 2015 , allowing for at least a year of follow-up, to enable comparison with the measures reported in other published screening studies. Linkage between the BC Cancer Breast Screening database and the BC Cancer Registry was performed using each participant's unique personal health number.

\section{Cost-effectiveness modelling}

The cumulative sum of all additional costs and benefits attributed to the adoption of DBT plus DM versus DM alone was determined with the baseline assumptions that DBT plus DM screening exams cost an additional \$44 over DM and offer an absolute $2.2 \%$ recall rate reduction, and that the cancer detection rate increased by 1.6 per 1000 scans. ${ }^{18}$ For timedependent transitions, we used the shape and slope parameters from Weibull regression to determine the transition probabilities. Outcomes from ever-screened patients who developed breast cancer were used to estimate long-term mortality and treatment costs that could be expected for screening with DBT plus DM versus DM alone. In the cost analysis, we used data 
from 809 patients in the screening cohort who developed breast cancer within the observation period. The modelling parameters and assumptions are provided in Table 1.

The base-case scenario assumed that the intervention offered a $2.2 \%$ absolute reduction in recall rates, as reported in a recent meta-analysis of observational screening studies on
DBT in North America. ${ }^{18}$ The model predicted the additional costs and QALYs gained from adding DBT to DM, compared with DM, following a participant's index screening exam. The ratio of the additional costs to QALYs gained was reported as the incremental cost-effectiveness ratio (ICER). A series of screening scenarios was evaluated deterministically

\section{Table 1: Model parameters and assumptions}

\begin{tabular}{|c|c|c|}
\hline Parameter & Description & Source data and assumptions \\
\hline \multicolumn{3}{|c|}{ Breast cancer screening and diagnosis } \\
\hline Screening utilization rates & $\begin{array}{l}\text { Biennial screening exams for new screening participants, } \\
\text { assuming } 100 \% \text { return rates over } 25 \text { years }\end{array}$ & $\begin{array}{l}\text { Maximum additional costs and the } \\
\text { average age of new mammography } \\
\text { screening participants }\end{array}$ \\
\hline Abnormal index exam rate & $\begin{array}{l}\text { Percentage of index mammograms identified as abnormal; } \\
19.5 \% \text { of all index exams }\end{array}$ & Screening cohort, index exam \\
\hline $\begin{array}{l}\text { Subsequent abnormal } \\
\text { exam rate }\end{array}$ & Probability of a subsequent abnormal exam; $9.0 \%$ & Screening cohort, subsequent exams \\
\hline $\begin{array}{l}\text { Detection after an abnormal } \\
\text { exam }\end{array}$ & $\begin{array}{l}\text { Time-dependent rate of developing breast cancer following } \\
\text { history of any abnormal exam result }\end{array}$ & $\begin{array}{l}\text { Screening cohort linked with breast } \\
\text { cancer cohort }\end{array}$ \\
\hline $\begin{array}{l}\text { Incremental cancer } \\
\text { detection rate }\end{array}$ & $\begin{array}{l}\text { Additional incidences of low-risk breast cancer applied to the } \\
\text { intervention arm attributed to increased cancer detection rates } \\
\text { from DBT plus DM over DM alone (an additional } 1.6 \text { per 1000), } \\
\text { applied biennially over } 25 \text { years }\end{array}$ & $\begin{array}{l}\text { Parameter assumption based on } \\
\text { meta-analysis }^{18}\end{array}$ \\
\hline Undetected breast cancer & $\begin{array}{l}\text { Time-dependent rate of developing breast cancer in the } \\
\text { absence of any abnormal exam result, by high- or low-risk } \\
\text { breast cancer }\end{array}$ & $\begin{array}{l}\text { Screening cohort linked with breast } \\
\text { cancer cohort }\end{array}$ \\
\hline $\begin{array}{l}\text { Absolute recall rate } \\
\text { reduction }\end{array}$ & $\begin{array}{l}\text { Absolute recall rate reduction from meta-analysis of } \\
\text { observational trials for the use of DBT versus DM }(2.2 \%) \text {, } \\
\text { applied biennially over } 25 \text { years }\end{array}$ & $\begin{array}{l}\text { Parameter assumption based on } \\
\text { meta-analysis }^{18}\end{array}$ \\
\hline \multicolumn{3}{|l|}{ Mortality } \\
\hline Survival & $\begin{array}{l}\text { Long-term survival for ever-screened participants, after } \\
\text { diagnosis, by high- or low-risk breast cancer }\end{array}$ & Breast cancer cohort \\
\hline Background mortality & $\begin{array}{l}\text { Age- and sex-specific mortality adjustments by } 5 \text {-year age } \\
\text { groupings }\end{array}$ & $\begin{array}{l}\text { Statistics Canada data for female } \\
\text { mortality by age, in BC }\end{array}$ \\
\hline \multicolumn{3}{|l|}{ Costs } \\
\hline Screening & $\begin{array}{l}\$ 125 \text { for DM; } \$ 169 \text { for combined DM and DBT, applied } \\
\text { biennially, over } 25 \text { years }\end{array}$ & $\begin{array}{l}\text { Established billing fees for Alberta } \\
\text { Health Services* }\end{array}$ \\
\hline Diagnostic evaluation & $\$ 550$ following the first abnormal exam & Mean cost for investigation in $\mathrm{BC}^{*}$ \\
\hline Treatment costs & Health state-specific costs, in 2019 Canadian dollars & $\begin{array}{l}\text { Resource utilization rates and unit } \\
\text { costs for screening participants who } \\
\text { had breast cancer }\end{array}$ \\
\hline \multicolumn{3}{|l|}{ Utilities } \\
\hline $\begin{array}{l}\text { Screening with normal } \\
\text { exam results }\end{array}$ & $\begin{array}{l}\text { Quality of life expected for screening with normal exam results, } \\
0.006 \text { decrease in utility score for } 1 \text { week after having a } \\
\text { mammogram }(0.994)\end{array}$ & Matched CISNET assumption† \\
\hline $\begin{array}{l}\text { Screening with an abnormal } \\
\text { exam result }\end{array}$ & $\begin{array}{l}\text { Quality of life following an abnormal exam result. Year } 1 \text {, utility = } \\
0.990 \text { ( } 5 \text { wk of disutility); years } 2-40 \text { returns to } 1.000\end{array}$ & $\begin{array}{l}\text { CISNET assumptions for false } \\
\text { positive exams } \dagger\end{array}$ \\
\hline Low-risk breast cancer & Utility weight of 0.900 for 2 years, then returns to 1.000 & $\begin{array}{l}\text { CISNET assumptions for localized } \\
\text { breast cancer and expert opiniont }\end{array}$ \\
\hline High-risk breast cancer & $\begin{array}{l}\text { Utility weight of } 0.750 \text { for the first } 13 \text { years, then } 0.600 \text { for years } \\
14-40 .\end{array}$ & $\begin{array}{l}\text { CISNET assumptions for advanced } \\
\text { breast cancer and expert opiniont }\end{array}$ \\
\hline
\end{tabular}


to define isolated parameter uncertainty attributable to variation in absolute reductions in recall rates, variation in screening costs, cancer detection rates that might be expected in different population subgroups (i.e., participants aged $<50 \mathrm{yr}$ ) or different regional outcomes and potential reductions in mortality from breast cancer. We also explored impacts from uncertainty around the disutility parameter to evaluate the quality-of-life assumptions for participants with abnormal exam results or overdiagnosis of breast cancer that is not life-threatening.

Cost-effectiveness was directly calculated from the modelled cohort. All future costs and benefits were discounted to net present value at a rate of $3 \%$ per year. We performed a probabilistic sensitivity analysis to simulate a range of possible ICER estimates by sampling from parameter distributions (Appendix 1). A standard threshold for acceptability of \$100 000 per QALY was selected for comparison with commonly cited thresholds of acceptability for breast screening in the published literature.

\section{Statistical analysis}

We used $\chi^{2}$ tests to detect differences in rates of histologic subgroups between high- and low-risk breast cancer to characterize the cohort members entering either of these breast cancer health states in the model and for comparison between the breast cancer costing and outcomes data sets. Mann-Whitney rank-sum tests were used to distinguish differences in mean costs for breast cancer treatment across low- and high-risk subgroups, differences between means in the cohort data and differences in mean follow-up time for low- versus high-risk breast cancer cost data. We estimated the odds ratio of a cancer diagnosis or subsequent abnormal exam using multivariable logistic regression models that adjusted for age and the baseline exam result. All tests of statistical significance report a $p$ value from 2 -sided tests, with a $5 \%$ threshold. The model was programmed with TreeAge Pro, version 2020.

\section{Ethics approval}

The study was approved by the University of British Columbia's Research Ethics Board (H17-03064).

\section{Results}

A total of 112249 participants were in the screening cohort with index mammograms recorded over the observation period. Their baseline demographic characteristics are provided in Table 2 . The mean age for the onset of screening with the index exam was 49.3 years, and most people in the cohort $(61.2 \%)$ had their first exam between age 40 and 49 years. The average recall rate was higher for index exams versus all subsequent exams (19.5\% v. $9.0 \%)$, and the chances of having a subsequent abnormal exam was higher after an abnormal versus normal index exam (odds ratio 1.24, 95\% confidence interval 1.14-1.35).

Of the 88975 screening participants with at least 1 year of follow-up, 592 had breast cancer detected within 1 year of
Table 2: Baseline demographic characteristics and screening exam results for new screening participants with an index screening exam from 2012 to 2017

\begin{tabular}{|c|c|}
\hline Characteristic & $\begin{array}{l}\text { No. }(\%) \text { of } \\
\text { participants* } \\
n=112249\end{array}$ \\
\hline \multicolumn{2}{|l|}{ Age at index exam, yr } \\
\hline Mean (range) & $49.3(40-74)$ \\
\hline $40-49$ & $68703(61.2)$ \\
\hline $50-59$ & $27976(24.9)$ \\
\hline $60-69$ & $13688(12.2)$ \\
\hline $70-75$ & $1902(1.7)$ \\
\hline \multicolumn{2}{|l|}{ Ethnicity† } \\
\hline European or British ancestry & $56706(50.5)$ \\
\hline East or Southeast Asian & $27614(24.6)$ \\
\hline South Asian & $7783(6.9)$ \\
\hline Aboriginal & $2867(2.5)$ \\
\hline West Asian & $2130(1.9)$ \\
\hline All others (including multiple ethnicities) & $10848(9.7)$ \\
\hline Not reported or unknown & $7319(6.5)$ \\
\hline \multicolumn{2}{|l|}{ Breast density (at index exam)‡ } \\
\hline$A$ & $10057(9.0)$ \\
\hline B & $24547(21.9)$ \\
\hline $\mathrm{C}$ & $27977(24.9)$ \\
\hline $\mathrm{D}$ & $9000(8.0)$ \\
\hline Missing & 40668 (36.2) \\
\hline \multicolumn{2}{|l|}{ Index exam year } \\
\hline 2012 & $9279(8.3)$ \\
\hline 2013 & $13558(12.1)$ \\
\hline 2014 & $19473(17.4)$ \\
\hline 2015 & $21869(19.5)$ \\
\hline 2016 & $23979(21.4)$ \\
\hline 2017 & $24091(21.5)$ \\
\hline \multicolumn{2}{|l|}{ Recall rate } \\
\hline $\begin{array}{l}\text { Index exam abnormal/total index exams } \\
\text { (\% total index exams) }\end{array}$ & $\begin{array}{c}21894 / 112 \\
(19.5)\end{array}$ \\
\hline $\begin{array}{l}\text { Subsequent abnormal exams/total } \\
\text { subsequent exams (\% of all subsequent) }\end{array}$ & 4965/55 $304(9.0)$ \\
\hline \multicolumn{2}{|l|}{ Completion rate (\% total) } \\
\hline Index exam & $112249(100.0)$ \\
\hline First subsequent & 40019 (35.7) \\
\hline Second subsequent & $11508(10.3)$ \\
\hline Third subsequent & $3037(2.7)$ \\
\hline Fourth subsequent & $632(0.6)$ \\
\hline Fifth subsequent & $108(0.1)$ \\
\hline \multicolumn{2}{|c|}{$\begin{array}{l}\text { *Unless stated otherwise. } \\
\text { †All self-reported responses to questions about race or ethnicity on registration with } \\
\text { BC Cancer Breast Screening totalling more than } 1.0 \% \text { for any subgroup were included. } \\
\text { łBreast Imaging Reporting and Data System (BI-RADS; www.acr.org/ } \\
\text { Clinical-Resources/Reporting-and-Data-Systems/Bi-Rads). }\end{array}$} \\
\hline
\end{tabular}


an abnormal index exam. The cancer detection rate was 6.7 per 1000 for abnormal index exams and 1.7 per 1000 for all subsequent abnormal exams. There were 50 interval cancers that developed after a normal index screen, and the 1-year interval cancer rate was 0.57 per 1000 for index exams and 0.12 per 1000 for subsequent exams. Of the cancers detected within 1 year of an abnormal exam, $373(63.0 \%)$ were low risk, and 15 of the 50 interval cancers $(30.0 \%)$ were low risk.

\section{Resource utilization and cost analysis}

The costing cohort had lower proportions of hormone receptor-positive breast cancer and younger age at diagnosis than the breast cancer cohort, but similar histology and stage characteristics (Appendix 1). The difference was attributed to risks from age or menopausal status that distinguish new screening participants from all other patients with breast cancer who have screening exposure. The resource utilization rates and cost inputs shown in Table 3 indicate similar followup for patients in high-risk versus low-risk groups, over each of the 5 years analyzed for costs (all $p>0.1)$.

\section{Cost-effectiveness}

The model predicted that the addition of DBT to DM screening would result in an additional 0.027 QALY, with an average incremental cost difference of $\$ 470$ per person. The estimated ICER was $\$ 17149$ per QALY. The deterministic analysis showed that absolute reductions in recall rates had a major impact on cost-effectiveness; when this parameter was varied over the range of results reported in observational studies, either the intervention or the comparator would appear cost-effective (Figure 2). Increasing the costs to treat highrisk breast cancer and increasing cancer detection rate had only marginal impacts on the overall cost-effectiveness, owing to the low number of individuals who receive a breast cancer diagnosis relative to the high number that are screened.

The probabilistic sensitivity analysis showed that $95 \%$ of 100000 iterations simulated fell below the commonly referenced willingness to pay threshold of $\$ 100000$ per QALY. Full details for both sensitivity analyses are provided in Appendix 1. If DBT plus DM reduces absolute recall rates by at least $2.1 \%$, and the additional cost of providing DBT exams is not higher than the established reimbursement fees, the technology would be considered a cost-effective addition to DM screening.

\section{Interpretation}

The cost-effectiveness of adding DBT to DM screening depends critically on the ability of DBT to improve the specificity of DM - a screening intervention with low positive predictive values and potential for overdiagnosis. Our analysis was most sensitive to parameters related to screening exam results and relatively insensitive to parameters related to cancer detection; specifically, there was negligible impact from varying rates of breast cancer deaths, higher treatment costs or disutility from overdiagnosis of low-risk breast cancer on their own. Using assumptions from meta-analysis, we find that the average incremental benefits provided by DBT plus DM are small (0.027 QALY per person), driven by DBT plus DM enabling a lower probability of transitions to the ever-abnormal health state, and this benefit is achieved with an incremental cost of $\$ 470$ per person.

Our findings add to the existing knowledge offered by published microsimulation models by identifying recall rates as the parameter with the most impact. The main difference with our modelling approach is the distinction of an "everabnormal" health state. The strong economic effects of recall rate reductions may be washed out if the history of an abnormal exam is not accounted for as an independent risk factor. Most breast cancer screening participants can expect to receive an abnormal screen if they participate long enough with the current DM technology. ${ }^{29}$ Parameterizing recall rates independently aligns with knowledge of a higher risk of developing breast cancer after having had an abnormal exam. ${ }^{30}$ There may also be subtle differences attributed to our use of data from patients with breast cancer who had prior screening exposure, rather than using whole registry data for all patients with breast cancer, regardless of screening history. Members of our research group have found that breast cancer outcomes are better for participants of screening mammography than for those not exposed to screening, and the treatment was less intensive. ${ }^{31}$

Recall rate reductions vary widely in observational DBT studies. An early population-based study in the US suggests that DBT plus DM will be able to replicate observational findings. ${ }^{32}$ Definitive outcomes from the ongoing randomized Tomosynthesis Mammographic Imaging Screening Trial (NCT02616432) will, however, clarify the diagnostic accuracy of DBT screening and its ability to improve the stage distribution of screen-detected breast cancer. Central to these results will be the ability of DBT plus DM to reduce interval cancer rates, which are more likely to be diagnosed as high-risk breast cancer. Recall rate reductions are also a function of breast cancerspecific risk factors. Age and family history, for example, are important predictors of aggressive forms of breast cancer that occur with overall low incidence rates before age 50. The evidence on individual risk factors and tailored screening strategies is emerging, and widespread mammography screening below age 50 is not recommended at this time. ${ }^{19,21}$

Improving the positive predictive value of breast cancer screening has the potential to improve program efficiency and there are several tools on the technology development horizon that aim to do so. ${ }^{28}$ Population-based risk prediction and predictive imaging models could improve the efficiency of breast screening.

\section{Limitations}

Our study used data available for screening participants aged 40-74 who used either a fixed-location mammography clinic or mobile breast screening vans that service BC. 
Research

Table 3: Resource utilization rates and costs for breast cancer treatment

\begin{tabular}{|c|c|c|c|c|}
\hline Health state & Year & Resource & $\begin{array}{c}\text { Resource } \\
\text { utilization rate } \\
\text { (per person) }\end{array}$ & Mean cost $(95 \% \mathrm{Cl}), \$$ \\
\hline \multirow[t]{22}{*}{ Low-risk breast cancer } & \multirow[t]{5}{*}{1} & Surgery & 1.00 & 7312 (7111 to 7512$)$ \\
\hline & & Genetic testing* & 0.51 & 2719 (2480 to 2957 ) \\
\hline & & Systemic therapy & 0.59 & 3008 (2085 to 3931$)$ \\
\hline & & Radiotherapy & 0.51 & 4283 (3893 to 4667$)$ \\
\hline & & End-of-life breast cancer care & NR & 0 \\
\hline & \multirow[t]{4}{*}{2} & Surgery & NR & 85 (17 to 153) \\
\hline & & Systemic therapy & 0.53 & 1577 (999 to 2156) \\
\hline & & Radiotherapy & 0 & $54(-22$ to 131$)$ \\
\hline & & End-of-life breast cancer care & NR & 0 \\
\hline & \multirow[t]{4}{*}{3} & Surgery & 0.06 & $40(-16$ to 96$)$ \\
\hline & & Systemic therapy & 0.48 & 450 (123 to 776$)$ \\
\hline & & Radiotherapy & NR & $90(-50$ to 231$)$ \\
\hline & & End-of-life breast cancer care & NR & 0 \\
\hline & \multirow[t]{4}{*}{4} & Surgery & 0 & $213(-206$ to 634$)$ \\
\hline & & Systemic therapy & 0.50 & 241 (137 to 346$)$ \\
\hline & & Radiotherapy & 0.01 & $120(-50$ to 288$)$ \\
\hline & & End-of-life breast cancer care & NR & $214(-106$ to 634$)$ \\
\hline & \multirow[t]{4}{*}{5} & Surgery & 0 & $79(-77$ to 235$)$ \\
\hline & & Systemic therapy & 0.48 & $516(-251$ to 1285$)$ \\
\hline & & Radiotherapy & 0 & 0 \\
\hline & & End-of-life breast cancer care & NR & 0 \\
\hline & $6-40$ & Continue year 5 & & \\
\hline \multirow[t]{21}{*}{ High-risk breast cancer } & \multirow[t]{4}{*}{1} & Surgery & 0.96 & 7881 (7547 to 8216$)$ \\
\hline & & Systemic therapy & 0.98 & 19664 (17 496 to 21832$)$ \\
\hline & & Radiotherapy & 0.79 & 9019 (8457 to 9581$)$ \\
\hline & & End-of-life breast cancer care & NR & $274(-106$ to 655$)$ \\
\hline & \multirow[t]{4}{*}{2} & Surgery & 0.02 & 111 (10 to 213 ) \\
\hline & & Systemic therapy & 0.83 & 7718 (5736 to 9699$)$ \\
\hline & & Radiotherapy & NR & 285 (102 to 468$)$ \\
\hline & & End-of-life breast cancer care & NR & $277(-107$ to 621$)$ \\
\hline & \multirow[t]{4}{*}{3} & Surgery & 0 & 0 \\
\hline & & Systemic therapy & 0.76 & 4004 (1967 to 6312) \\
\hline & & Radiotherapy & NR & 106 (0 to 212$)$ \\
\hline & & End-of-life breast cancer care & NR & 960 (124 to 1795$)$ \\
\hline & \multirow[t]{4}{*}{4} & Surgery & 0 & 0 \\
\hline & & Systemic therapy & 0.70 & 1574 (404 to 2743$)$ \\
\hline & & Radiotherapy & 0.01 & $112(-14$ to 237$)$ \\
\hline & & End-of-life breast cancer care & NR & $984(-124$ to 2095$)$ \\
\hline & \multirow[t]{4}{*}{5} & Surgery & 0 & 0 \\
\hline & & Systemic therapy & 0.70 & $1619(-76$ to 3314$)$ \\
\hline & & Radiotherapy & 0 & 0 \\
\hline & & End-of-life breast cancer care & NR & 647 (-630 to 1925$)$ \\
\hline & $6-40$ & Continue year 5 & & \\
\hline
\end{tabular}




\section{Base-case scenario: \$17 149/QALY}

Low recall rate reduction ( $1 \%$ for index and all subsequent examinations)

Low recall rate reduction ( $1 \%$ for index examination only)

High recall rate reduction ( $7.7 \%$ for index and all subsequent examinations)

High recall rate reduction ( $7.7 \%$ for index examination only)

DBT increases overdiagnosis of low-risk breast cancer by $10 \%$

High cost of DBT (\$75)

Low cost of DBT (\$15)

DBT reduces overdiagnosis of low-risk breast cancer by $10 \%$

Lower quality of life after abnormal examination result

Cost to treat high-risk breast cancer doubles

Lower quality of life after low-risk breast cancer

Higher breast cancer mortality rate ( $20 \%$, both study arms)

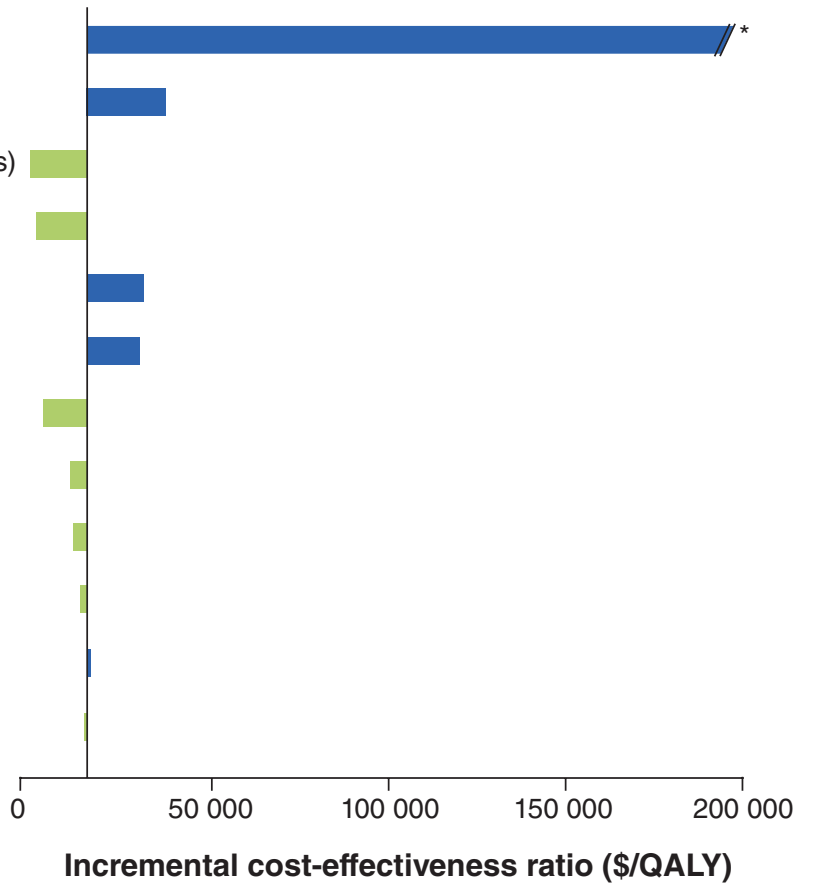

Figure 2: Variability in cost-effectiveness of scenarios simulated in the deterministic sensitivity analysis. Note: DBT = digital breast tomosynthesis, QALY = quality-adjusted life year. In the scenario marked with an asterisk ( $\left.{ }^{*}\right)$, the incremental cost-effectiveness ratio is truncated at a maximum of $\$ 200000$ per QALY in this figure.

Breast density assessment was not adopted as routine screening practice in BC until 2017; therefore, our analysis did not adjust for this variable. If DBT can reduce recall rates in some screening participants with high breast density but increase recall in others, then cost-effectiveness results need to be stratified to account for heterogeneity in breast density.

Our study is limited by the amount of follow-up data available for simulating long-term breast cancer outcomes for screening participants. The screening literature in general is limited by the absence of patient-level data on disutility from abnormal exam results or low-risk breast cancer that may not have affected mortality if left untreated. There is emerging literature on disutility for cancer screening that cites methodological challenges related to obtaining this information from screening participants accurately. ${ }^{33}$ These data therefore may not be visible in standard economic evaluations that rely on standard health utility instruments.

\section{Conclusion}

If DBT can reduce recall rates and does not introduce additional screening costs, it is likely to be considered costeffective. Canadian evidence showing recall rate reductions with DBT is required.

\section{References}

1. Bernardi D, Macaskill P, Pellegrini M, et al. Breast cancer screening with tomosynthesis (3D mammography) with acquired or synthetic $2 \mathrm{D}$ mammography compared with $2 \mathrm{D}$ mammography alone (STORM-2): a populationbased prospective study. Lancet Oncol 2016;17:1105-13.

2. Aujero MP, Gavenonis SC, Benjamin R, et al. Clinical performance of synthesized two-dimensional mammography combined with tomosynthesis in a large screening population. Radiology 2017;283:70-6.

3. Conant EF, Beaber EF, Sprague BL, et al. Breast cancer screening using tomosynthesis in combination with digital mammography compared to digital mammography alone: a cohort study within the PROSPR consortium. Breast Cancer Res Treat 2016;156:109-16.

4. Destounis S, Arieno A, Morgan R. Initial experience with combination digital breast tomosynthesis plus full field digital mammography or full field digital mammography alone in the screening environment. 7 Clin Imaging Sci 2014; 4:9. doi: 10.4103/2156-7514.127838.

5. Durand MA, Haas BM, Yao X, et al. Early clinical experience with digital breast tomosynthesis for screening mammography. Radiology 2015;274: 85-92.

6. Friedewald SM, Rafferty EA, Rose SL, et al. Breast cancer screening using tomosynthesis in combination with digital mammography. $7 A M A 2014$; 311:2499-507.

7. Greenberg JS, Javitt MC, Katzen J, et al. Clinical performance metrics of 3D digital breast tomosynthesis compared with 2D digital mammography for breast cancer screening in community practice. AfR Am 7 Roentgenol 2014; 203:687-93.

8. Haas BM, Kalra V, Geisel J, et al. Comparison of tomosynthesis plus digital mammography and digital mammography alone for breast cancer screening. Radiology 2013;269:694-700.

9. Lourenco AP, Barry-Brooks M, Baird GL, et al. Changes in recall type and patient treatment following implementation of screening digital breast tomosynthesis. Radiology 2015;274:337-42.

10. McCarthy AM, Kontos D, Synnestvedt M, et al. Screening outcomes following implementation of digital breast tomosynthesis in a general-population 
screening program. 7 Natl Cancer Inst 2014;106:dju316. doi: 10.1093/jnci/ dju316.

11. Powell JL, Hawley JR, Lipari AM, et al. Impact of the addition of digital breast tomosynthesis (DBT) to standard 2D digital screening mammography on the rates of patient recall, cancer detection, and recommendations for short-term follow-up. Acad Radiol 2017;24:302-7.

12. Rose SL, Tidwell AL, Bujnoch LJ, et al. Implementation of breast tomosynthesis in a routine screening practice: an observational study. $A 7 R A m \mathcal{F}$ Roentgenol 2013;200:1401-8.

13. Sharpe RE Jr, Venkataraman S, Phillips J, et al. Increased cancer detection rate and variations in the recall rate resulting from implementation of $3 \mathrm{D}$ digital breast tomosynthesis into a population-based screening program. Radiology 2016;278:698-706.

14. Starikov A, Drotman M, Hentel K, et al. 2D mammography, digital breast tomosynthesis, and ultrasound: Which should be used for the different breast densities in breast cancer screening? Clin Imaging 2016;40:68-71.

15. Ciatto S, Houssami N, Bernardi D, et al. Integration of 3D digital mammography with tomosynthesis for population breast-cancer screening (STORM): a prospective comparison study. Lancet Oncol 2013;14:583-9.

16. Lang K, Andersson I, Rosso A, et al. Performance of one-view breast tomosynthesis as a stand-alone breast cancer screening modality: results from the Malmo Breast Tomosynthesis Screening Trial, a population-based study. Eur Radiol 2016;26:184-90.

17. Skaane P, Bandos AI, Gullien R, et al. Prospective trial comparing full-field digital mammography (FFDM) versus combined FFDM and tomosynthesis in a population-based screening programme using independent double reading with arbitration. Eur Radiol 2013;23:2061-71.

18. Marinovich ML, Hunter KE, Macaskill P, et al. Breast cancer screening using tomosynthesis or mammography: a meta-analysis of cancer detection and recall. 7 Natl Cancer Inst 2018;110:942-9.

19. Siu AL, Force USPST. Screening for breast cancer: U.S. Preventive Services Task Force recommendation statement. Ann Intern Med 2016;164:279-96.

20. Melnikow JFJ, Miglioretti D, Whitlock EP, et al. Screening for breast cancer with digital breast tomosynthesis. Rockville (MD): Agency for Healthcare Research and Quality; 2016.

21. Klarenbach S, Sims-Jones N, Lewin G, et al. Recommendations on screening for breast cancer in women aged 40-74 years who are not at increased risk for breast cancer. CMA7 2018;190:E1441-E51.

22. Lenzer J. 3D mammography is on the upswing in the US, as experts argue about its value. $B M 7$ 2019;366:14506.

23. Gilbert FJ, Tucker L, Young KC. Digital breast tomosynthesis (DBT): a review of the evidence for use as a screening tool. Clin Radiol 2016;71:141-50.

24. Drummond M, Schulpher M, Claxton C, et al. Methods for the economic evaluation of bealth care programmes. 4th ed. London (UK): Oxford University Press; 2005.

25. Lee CI, Cevik M, Alagoz O, et al. Comparative effectiveness of combined digital mammography and tomosynthesis screening for women with dense breasts. Radiology 2015;274:772-80.

26. Lowry KP, Trentham-Dietz A, Schechter CB, et al. Long-term outcomes and cost-effectiveness of breast cancer screening with digital breast tomosynthesis in the United States. 7 Natl Cancer Inst 2020;112:582-9.

27. Kalra VB, Wu X, Haas BM, et al. Cost-effectiveness of tomosynthesis in annual screening mammography. A7R Am 7 Roentgenol 2016;207:1152-5.
28. Geras KJ, Mann RM, Moy L. Artificial intelligence for mammography and digital breast tomosynthesis: current concepts and future perspectives. Radiology 2019;293:246-59.

29. Coldman A, Phillips N, Wilson C, et al. Pan-Canadian study of mammography screening and mortality from breast cancer. 7 Natl Cancer Inst 2014; 106:dju261.

30. Engmann NJ, Golmakani MK, Miglioretti DL, et al. Population-attributable risk proportion of clinical risk factors for breast cancer. 7AMA Oncol 2017; 3:1228-36.

31. Brok W-LDD, Speers C, Gondara L, et al. Does the extent of therapy differ between breast cancers detected by screening mammogram and non-screening methods? 7 Clin Oncol 2017;35(Suppl 15):1544.

32. Conant EF, Barlow WE, Herschorn SD, et al. Association of digital breast tomosynthesis vs digital mammography with cancer detection and recall rates by age and breast density. FAMA Oncol 2019;5:635-42.

33. Bromley HL, Mann GB, Petrie D, et al. Valuing preferences for treating screen detected ductal carcinoma in situ. Eur 7 Cancer 2019;123:130-7.

Affiliations: Department of Integrative Oncology (Cressman), BC Cancer Research Centre, Vancouver, BC; Faculty of Health Sciences (Cressman), Simon Fraser University, Burnaby, BC; Cancer Screening (Mar, Sam, Kan), BC Cancer; Department of Radiology (Mar), Division of Medical Oncology (Lohrisch) and School of Population and Public Health (Spinelli), Faculty of Medicine, University of British Columbia; Department of Medical Oncology (Lohrisch), BC Cancer; Division of Population Oncology (Spinelli), BC Cancer, Vancouver, BC

Contributors: Sonya Cressman, Lisa Kan, Janette Sam, John Spinelli, Caroline Lohrisch and Colin Mar contributed to the conceptualization of the work, acquisition of the data, its analysis and/or the interpretation of the data. All authors have contributed to the drafting and revision of the manuscript and approved the final version to be published. All authors agree to be accountable for aspects of the work.

Funding: This study received funding from BC Cancer Breast Screening. The funder manages the provincial breast screening budget in BC.

Content licence: This is an Open Access article distributed in accordance with the terms of the Creative Commons Attribution (CC BY-NC-ND 4.0) licence, which permits use, distribution and reproduction in any medium, provided that the original publication is properly cited, the use is noncommercial (i.e., research or educational use), and no modifications or adaptations are made. See: https://creativecommons.org/licenses/ by-nc-nd/4.0/

Data sharing: Data for this study are available as aggregated modelling parameters on request.

Supplemental information: For reviewer comments and the original submission of this manuscript, please see www.cmajopen.ca/content/9/2/ E443/suppl/DC1. 